\title{
Quantificação da produção científica sobre Design Colaborativo e Sustentabilidade
}

Quantification of the scientific production on collaborative design

and sustainability

\author{
Natalia Maria Devergenes \\ Universidade Estadual de Londrina \\ ndevergenes@gmail.com
}

Ana Luisa Boavista Lustosa Cavalcante

Universidade Estadual de Londrina

anaboavista@gmail.com

\section{PROJËTICA}

\section{COMO CITAR ESTE ARTIGO:}

DEVERGENES, Natalia Maria; CAVALCANTE, Ana Luisa Boavista Lustosa. Quantificação da produção científica sobre design colaborativo e sustentabilidade. Projética, Londrina, v. 12, n. 1, p. 246-269, 2021

DOI: 10.5433/2236-2207.2021v12n1p246

Submissão: $14 / 08 / 19$

Aceite: 28/11/19 
RESUMO: Este artigo tem como principal objetivo demonstrar a produção científica sobre Design Colaborativo e Sustentabilidade. Para tanto, realizou-se: (1) uma Revisão Bibliográfica Sistemática (RBS), para indicar o estado da arte; (2) uma análise diacrônica, para indicar a quantidade de trabalhos por ano; e (3) uma análise de cocitação, para indicar quais autores possuem maior proximidade teóricoconceitual. Os resultados demonstram a numerosa presença de correntes teóricas interdisciplinares, que relacionam tecnologia, ambiente e sociedade; e lacunas em correntes teóricas dedicadas à sustentabilidade social.

Palavras-chave: Design colaborativo. Sustentabilidade. Design social. Análise de cocitação.

ABSTRACT: This article aims to demonstrate the scientific production on Collaborative Design and Sustainability. To this end, we conducted: (1) a Systematic Bibliographic Review (RBS) to indicate the state of the art; (2) a diachronic analysis to indicate the amount of work per year; and (3) a cocitation analysis to indicate which authors have greater theoretical and conceptual proximity. Results demonstrate the presence of numerous interdisciplinary theoretical currents, which relate technology, environment and society; and gaps in theoretical currents dedicated to social sustainability.

Keywords: Collaborative design. Sustainability. Social design. Cocitation analysis.

\section{INTRODUÇÃO}

O termo Design para a sustentabilidade social surge para melhor definir o que antes era chamado de "design social": uma prática do design com preocupações voltadas a grupos sociais que são de alguma forma marginalizados na sociedade (CAVALCANTE, 2014). Também é recente a prática do design colaborativo, ou co-design, uma alternativa ao processo "tradicional" de design mais utilizado na 
modernidade cujo funcionamento é de forma individual com divisão das tarefas e atividades.

Entende-se que o processo do design colaborativo pode ser um potencializador das atividades realizadas pelas comunidades criativas formadas por grupos sociais marginalizados (MANZINI, 2008). À vista disso, necessita-se de uma revisão bibliográfica sistemática para verificar se e como esses conceitos estão relacionados na comunidade científica de design, já que ambos os assuntos ‘Design Colaborativo' e 'Design para a Sustentabilidade Social' são tão recentes. Quais são os principais autores na área até o momento? Quais as relações teórico-conceituais entre eles?

Este trabalho tem como objetivo geral demonstrar como está sendo tratada a relação dos conceitos "Design para a Sustentabilidade", "Design Social" e "Design Colaborativo" na comunidade científica. Especificamente, pretende-se realizar uma revisão bibliográfica sistemática (RBS) no portal de periódicos Scopus com o uso dos três termos e analisar as citações e cocitações para indicar quais são os autores principais das áreas e quais possuem maior proximidade teóricoconceitual.

A análise de citações e cocitações é um recurso quantitativo que permite a avaliação métrica da produção científica em determinada área do conhecimento. Com essa metodologia, identificam-se os autores mais citados (análise de citação) e se há relação teórico-conceitual entre tais autores em áreas diferentes de pesquisa (GRÁCIO; OLIVEIRA, 2013, p. 197). Este estudo é uma forte contribuição para o conhecimento das áreas design colaborativo e design para a sustentabilidade porque demonstra se ambos os conceitos possuem relação teórica entre si e onde há lacunas em que as pesquisas podem ser mais desenvolvidas dentro da temática. 
Quantificação da produção científica... e sustentabilidade DEVERGENES, N. M; CAVALCANTE, A. L. B. L

O termo Design para a sustentabilidade social surge para melhor definir o que antes era chamado de "design social": uma prática do design com preocupações voltadas a grupos sociais que são de alguma forma marginalizados na sociedade. 
Por serem áreas de estudo e prática recentes no design, pressupõe-se que ainda há muito a ser explorado. A compreensão dos aspectos básicos e autores principais das áreas design colaborativo e sustentabilidade é imprescindível para o desenvolvimento e amadurecimento de novas pesquisas e práticas em qualquer esfera de atuação do design: na ciência, no mercado e no ensino em qualquer instituição. Além disso, o fortalecimento de tais estudos e práticas carrega grande potencial de inovação social e sustentabilidade, beneficiando a sociedade como um todo.

\section{FUNDAMENTAÇÃO TEÓRICA}

Os projetos que se inserem no contexto do design contemporâneo isto é, pós-moderno - possuem características peculiares em relação aos outros. Entre elas está a interdisciplinaridade (MOURA, 2015, p. 68-69), que requere uma colaboração dentro do processo de desenvolvimento de produtos ou sistemas (MARTTILA, 2018, p. 57). A abordagem sistêmica, que considera que os desafios do design contemporâneo devem ser considerados em sua relação com outros problemas e desafios da sociedade, está fortemente relacionada com o conceito de sustentabilidade. Segundo Cavalcante et al. (2012) o termo "design para a sustentabilidade" é interdisciplinar porque envolve inevitavelmente as áreas ambiental, social, cultural, política e mercadológica. Nesse contexto contemporâneo e sustentável, o processo colaborativo se mostra a maneira mais coerente e efetiva de fazer design.

O termo "design social" carrega distintas perspectivas dos diferentes autores que tratam sobre o tema. Em 1972, Victor Papanek lançou o livro ‘Design for the Real World' (Design para o Mundo Real), inaugurando um paradigma do design que procura desenvolver produtos e sistemas para necessidades coletivas, sociais de países em desenvolvimento e grupos de pessoas com necessidades especiais (idosos, baixa renda, entre outros grupos marginalizados). Victor Margolin e Sylvia Margolin (2002, p. 24) apontam que a produção de Papanek 
contraria o paradigma do "modelo de mercado" que o design estava inserido desde a Revolução Industrial. No entanto, a produção científica no design que atende ao "modelo de mercado" é muito mais extensa do que a produção sobre o "modelo social". Logo, em seu artigo 'A "Social Model" of Design: Issues of Practice and Research' (Um "Modelo Social" de Design: Temas de Prática e Pesquisa), os autores definem uma agenda para futuras pesquisas e projetos dentro desse paradigma.

Mesmo que os conceitos "design social" e "design para o mercado" estejam inicialmente em oposição, na literatura e na prática eles se fundem. Entretanto, há uma motivação maior para distinguir as duas áreas na pesquisa, pois como argumenta Victor Margolin e Sylvia Margolin (2002, p. 25, tradução nossa):

Muitos produtos projetados para o mercado também atendem uma necessidade social porém nós argumentamos que o mercado não é capaz de suprir todas as necessidades sociais, principalmente no que se refere a populações que não constituem as classes com capacidade de consumo no mercado. Nós nos referimos aqui a pessoas de baixa renda ou necessidades especiais devido à terceira idade, problemas de saúde, ou deficiências de qualquer tipo. ${ }^{1}$

Há outros autores que questionam o termo "design social", como o designer brasileiro Joaquim Redig (2011, p. 92):

A partir da década de 1980, o curso da PUC-Rio passou a pregar a linha do "design social". Não entendo bem este termo, porque não existe design que não seja social - para a sociedade. Se não for, não é design. O que seria design não social? Design comercial? Design comercial que não for dirigido às necessidades da sociedade não é design.

[1] Many products designed for the market also meet a social need but we argue that the market does not, and probably cannot, take care of all social needs, as some relate to populations who do not constitute a class of consumers in the market sense. We refer here to people with low incomes or special needs due to age, health, or disability. 
Redig (2011) tem um posicionamento radical quando se trata do papel social do designer. Ele parte da premissa de que todos os projetos de design devem ser centrados no usuário (um ser humano), logo, são inerentemente sociais. Os projetos que têm como objetivo apenas o incentivo à venda e ao consumo, portanto, não são considerados design. Isso faz muito sentido quando voltamos às origens da atuação do designer como conhecemos hoje, o movimento construtivista e a escola Bauhaus, que aliaram a arte à tecnologia priorizando o bem-estar coletivo da classe social proletária (CURTIS, 2011).

Gui Bonsiepe (2011, p. 21) distingue as atuações do "modelo social" e "modelo de mercado", defendendo o chamado "design social" como um fortalecedor da democracia:

O humanismo projetual seria o exercício das capacidades projetuais para interpretar as necessidades de grupos sociais e elaborar propostas viáveis, emancipatórias, em forma de artefatos instrumentais e artefatos semióticos. Por que emancipatórios? Porque emancipatórios? Porque humanismo implica a redução da dominação e, no caso do design, atenção também aos excluídos, aos discriminados, como se diz eufemisticamente no jargão economista, os "economicamente menos favorecidos", ou seja, a maioria da população deste planeta.

É dentro desse tratamento que o conceito "design para a sustentabilidade social" existe: ele considera que o design por si só é social e que existe uma área de atuação nele que tem as necessidades da sociedade como maior prioridade (CAVALCANTE, 2014).

Manzini (2008) trabalha com o conceito de "design social" no tratamento da sustentabilidade em seu livro ‘Design para a inovação social e sustentabilidade'. O autor faz uma relação direta entre organizações colaborativas e sustentabilidade social em razão da alta potencialidade das comunidades de gerar conhecimentos e soluções para diversas situações e problemas. Assim, quanto maior a quantidade de comunidades criativas na sociedade, mais sustentável ela é. Além disso, 
O termo "design para a sustentabilidade" é interdisciplinar porque envolve inevitavelmente as áreas ambiental, social, cultural, política e mercadológica. Nesse contexto contemporâneo e sustentável, o processo colaborativo se mostra a maneira mais coerente e efetiva de fazer design. 
os conhecimentos alternativos que são gerados pelas comunidades criativas são eficientes para causar uma descontinuidade sistêmica no conhecimento hegemônico que é por essência insustentável. O papel social do designer é, então, de criar "soluções habilitantes" participativas para que a existência dessas comunidades criativas seja cada vez mais possível numa sociedade que é altamente padronizada.

A comunidade científica de design estabelece uma comunicação nas discussões teóricas por meio de termos que são ressignificados conforme o debate avança. A escolha dos termos "design colaborativo", "design social" e "sustentabilidade" foi feita com base nessa discussão teórica. Mesmo que o termo "design social" no contexto das produções contemporâneas seja redundante, ele foi incluído na busca para levantar trabalhos inseridos num contexto anterior a essa fase mais avançada do debate.

\section{METODOLOGIA}

A metodologia deste trabalho está pautada na pesquisa quantitativa bibliométrica, que analisa e relaciona os dados de uma pesquisa bibliográfica para melhor compreender a produção e a comunicação de uma área científica (GRÁCIO; OLIVEIRA, 2013). O recorte da área neste trabalho é a que trata os temas Design colaborativo e Sustentabilidade. A partir da revisão bibliográfica sistemática, pode-se identificar entre as referências de cada trabalho presente no resultado os autores mais citados e as situações de coautoria. As análises de citação e cocitação são as ferramentas deste estudo para o cumprimento do objetivo do trabalho.

Segundo Grácio e Oliveira (2013), a análise de citações indica a relação entre os pesquisadores de uma área do conhecimento e a comunicação entre eles. A citação indica que o autor de um trabalho concorda ou discorda das ideias do referenciado, e a frequência em que um autor foi citado indica sua visibilidade e relevância para a área. 
A análise de cocitações indica a frequência em que dois autores são citados juntamente em um mesmo trabalho. Isso indica quais autores possuem maior aproximação teórico-conceitual entre si, compreendendo-se que o autor do trabalho defende uma coerência nas ideias dos autores referenciados. Quanto maior o número de ocorrências em que dois autores são cocitados, maior é a proximidade teórico-conceitual deles, legitimada pelos agentes científicos que os referenciam (GRÁCIO; OLIVEIRA, 2013).

Para entendimento prévio do "estado da arte" que envolve Design colaborativo e Sustentabilidade, foi realizada uma revisão bibliográfica sistemática no portal de periódicos Scopus a partir das seguintes palavras-chave: sustainability AND "social design" OR "collaborative design" AND "codesign"'. A pesquisa foi delimitada nas áreas Social Sciences e Arts and Humanities, e inclui trabalhos publicados em qualquer lugar do mundo.

Os resultados foram exportados em formato.CSV com as informações relativas a referências para que tais dados sejam interpretados pelo software Vosviewer, que indicou as relações (clusters) entre as ocorrências de cocitação. Para recorte dos autores, foram selecionados os que possuem no mínimo 2 citações. Assim, dos 1671 autores referenciados, 243 foram selecionados. Para identificação da área de produção dos autores encontrados nas situações de coautoria, foi realizada uma pesquisa por autor na base de dados Scopus.

\section{ANÁLISE DOS RESULTADOS E DISCUSSÕES}

Os resultados da revisão bibliográfica incluem 37 trabalhos científicos até o ano de 2018 e todos foram considerados. A tabela a seguir indica os 10 autores mais citados: 
Tabela 1 - Autores mais citados em design colaborativo e sustentabilidade

\begin{tabular}{|c|c|c|c|}
\hline Autor & Ano & $\begin{array}{l}\text { Vezes } \\
\text { citado }\end{array}$ & $\begin{array}{l}\text { Título do } \\
\text { Artigo }\end{array}$ \\
\hline $\begin{array}{l}\text { BRUNDIERS, K.; WIEK, A.; } \\
\text { REDMAN, C. L. }\end{array}$ & 2010 & 155 & $\begin{array}{l}\text { Real-world learning opportunities in } \\
\text { sustainability: from classroom into the real } \\
\text { world }\end{array}$ \\
\hline $\begin{array}{l}\text { SCOTT, K.; BAKKER, C.; QUIST, } \\
\text { J. }\end{array}$ & 2016 & 62 & Designing change by living change \\
\hline DUFF, G. ET AL. & 2012 & 25 & $\begin{array}{l}\text { A collaborative design to adaptively manage } \\
\text { for landscape sustainability in north Australia: } \\
\text { Lessons from a decade of cooperative } \\
\text { research }\end{array}$ \\
\hline TOKER, Z. & 2007 & 24 & $\begin{array}{l}\text { Recent trends in community design: the } \\
\text { eminence of participation }\end{array}$ \\
\hline MEDWAY, P.; CLARK, B. & 2003 & 24 & $\begin{array}{l}\text { Imagining the building: Architectural design as } \\
\text { semiotic construction }\end{array}$ \\
\hline $\begin{array}{l}\text { CASTELNOVO, W.; MISURACA, } \\
\text { G.; SAVOLDELLI, A. }\end{array}$ & 2016 & 22 & $\begin{array}{l}\text { Smart Cities Governance: The Need for } \\
\text { a Holistic Approach to Assessing Urban } \\
\text { Participatory Policy Making }\end{array}$ \\
\hline RAHMAWATI, Y. ET AL. & 2014 & 11 & $\begin{array}{l}\text { An empirical model for successful } \\
\text { collaborative design towards sustainable } \\
\text { project development }\end{array}$ \\
\hline DE OLDE, E.M.; ET AL. & 2017 & 10 & $\begin{array}{l}\text { When experts disagree: the need to rethink } \\
\text { indicator selection for assessing sustainability } \\
\text { of agriculture }\end{array}$ \\
\hline LE DANTEC, C. A. & 2010 & 6 & $\begin{array}{l}\text { Situating design as social creation and cultural } \\
\text { cognition }\end{array}$ \\
\hline LE PAGE, C. ET AL. & 2015 & 5 & $\begin{array}{l}\text { Interactive simulations with a stylized scale } \\
\text { model to codesign with villagers an agent- } \\
\text { based model of bushmeat hunting in the } \\
\text { periphery of korup national park (Cameroon) }\end{array}$ \\
\hline
\end{tabular}

Fonte: Elaborado pela autora, 2018.

Embora o Portal Scopus tenvha abrangência nas línguas português do Brasil e inglês, todos os trabalhos encontrados estavam em língua inglesa. Isso indica uma produção escassa no Brasil, ou que as publicações aqui feitas não ganhem visibilidade para estarem nos resultados da pesquisa no portal. 
Entende-se que 37 é um número relativamente baixo para produções na área, mas deve se considerar que ela é extremamente recente, como indica a análise diacrônica da pesquisa:

Figura 1 - Análise diacrônica dos trabalhos encontrados no portal Scopus sobre design colaborativo e sustentabilidade

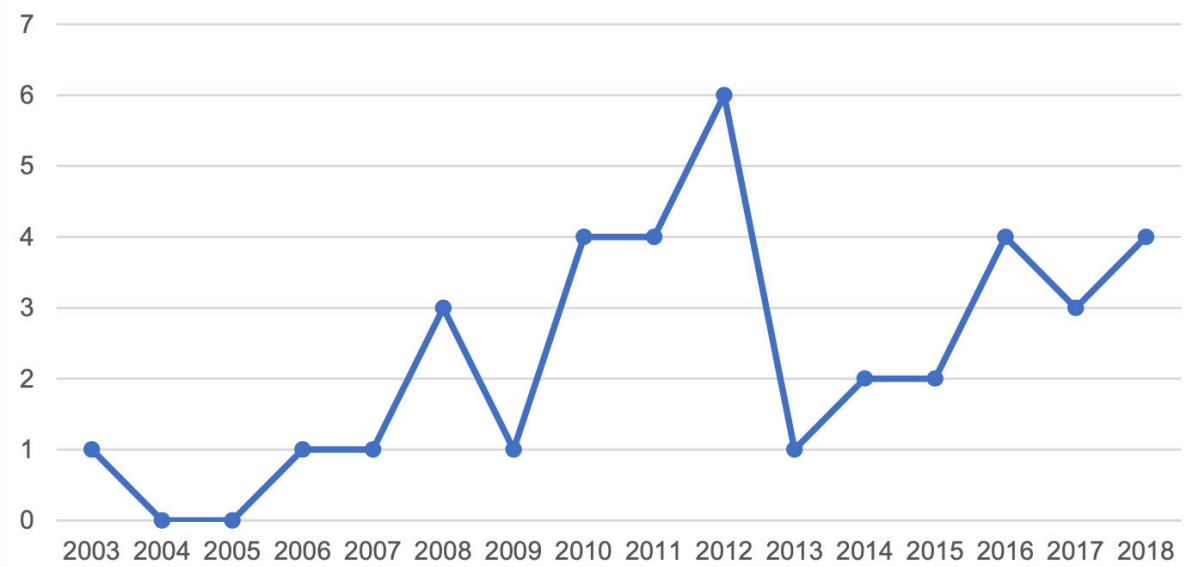

Fonte: elaborado pela autora, 2018.

A análise diacrônica indica quantos dos trabalhos do resultado dessa pesquisa foram publicados em cada ano. Percebe-se uma alta produção em 2012, que começou a crescer em 2008, ano de publicação do livro de Manzini ‘Design para a inovação social e sustentabilidade'. Em 2013, a produção de trabalhos sofreu uma queda, porém voltou a subir gradualmente até chegar a 4 artigos em 2018. Interessante notar que a produção é altamente recente, pois inicia-se (ainda que timidamente) em 2003, então está fortemente inserida no contexto pós-moderno do séc. XXI. 
A Tabela 2 indica os 10 autores mais citados entre as referências dos trabalhos da pesquisa bibliográfica. Tais dados foram gerados pelo software Vosviewer e os trabalhos em coautoria tiveram seus autores desmembrados:

Tabela 2 - Autores mais citados entre as referências dos trabalhos encontrados

\begin{tabular}{ll}
\hline Autores & $\mathbf{N}^{\circ}$ de citações \\
\hline SCHUNN, C. D. & 12 \\
\hline COLDING, J. & 9 \\
\hline FOLKE, C. & 8 \\
\hline PALETZ, S. B. F. & 7 \\
\hline BARTHEL, S & 6 \\
\hline CHRISTENSEN, B. T. & 6 \\
\hline BORGSTROM, S. & 5 \\
\hline ELMQVIST, T. & 5 \\
\hline ERNSTON, H. & 5 \\
\hline JEHN, K. A. & 5 \\
\hline
\end{tabular}

Fonte: Elaborado pela autora, 2018.

Christian D. Schunn é o autor mais citado, com 12 citações. Sua produção científica segundo o portal Scopus é extensa, com 208 trabalhos no total e 2941 citações em diferentes trabalhos. Sua área de atuação perpassa por Ciências Sociais, Psicologia, Ciência da Computação, Engenharia, Neurociência e Artes, para citar apenas alguns. É um autor que se mostra extremamente interdisciplinar, e sua produção mais recente (dezembro de 2012) relaciona a prática educacional com o design. Seguido de Schunn, encontra-se Johan Colding, que publica sobre sustentabilidade ambiental. Sua produção é de "apenas" 31 artigos, porém as citações são muito elevadas se comparadas à produção: o autor foi citado em 2881 trabalhos, segundo a plataforma Scopus.

Essa tabela, após ser gerada no Vosviewer, foi utilizada para gerar um mapa mental que permite a visualização das redes de cocitação entre os autores referenciados. Este é o resultado: 
Figura 2 - Análise diacrônica dos trabalhos encontrados no portal Scopus sobre design colaborativo e sustentabilidade

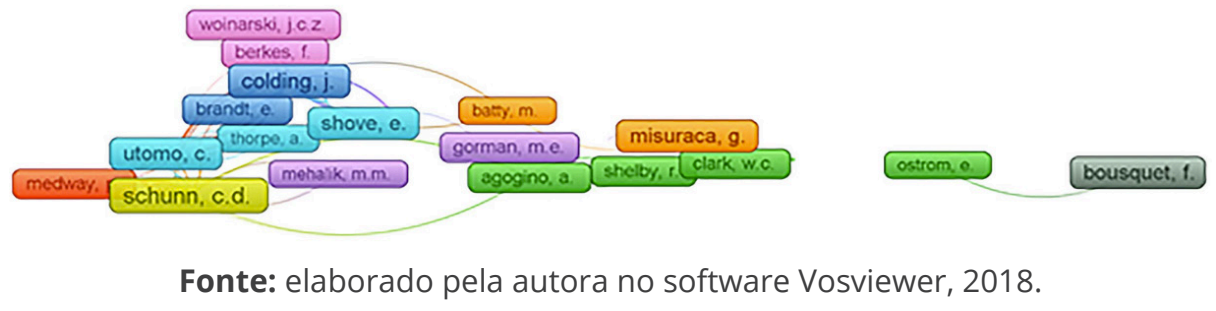

Na produção sobre Design Colaborativo e Sustentabilidade há 9 clusters, que são grupos de autores que são citados em conjunto. Cada cluster indica uma proximidade teórica; assim, os autores do cluster amarelo, por exemplo, são muito isolados, pois produzem quase sempre dentro da mesma corrente teórica, com apenas alguns autores que se aproximam de outros clusters. O principal autor, mais citado, do cluster amarelo, é Christian D. Schunn, que publica sobre educação e práticas colaborativas. Outro autor principal do cluster amarelo é Bo Thomas Christensen, que já publicou na revista 'Design Issues' artigos sobre design de interfaces digitais e processos colaborativos no design. Compreende-se, portanto, que o cluster amarelo refere-se a teorias relacionadas a atividades em comunidades, colaboração e educação em design.

Figura 3 - Principais autores do cluster amarelo

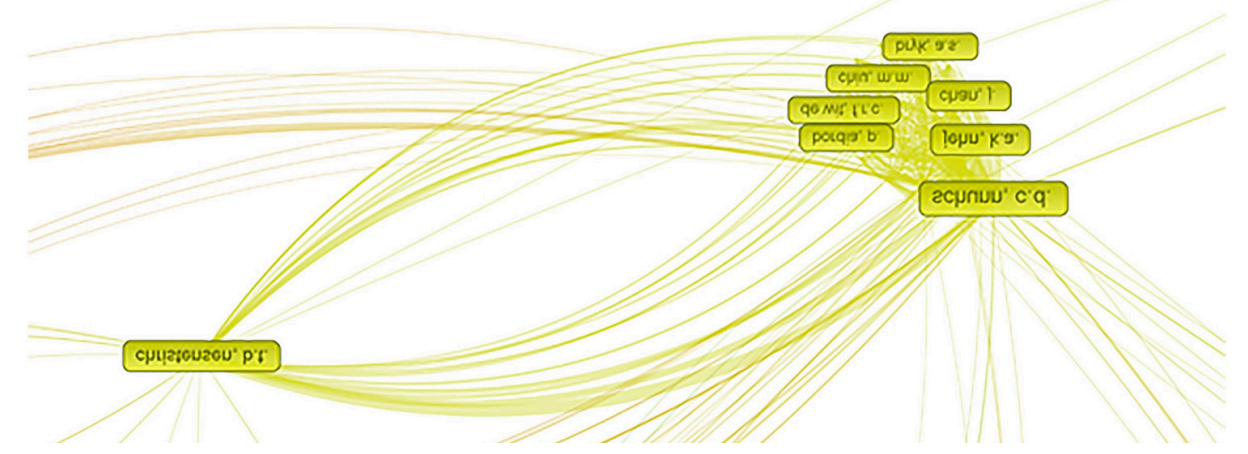

Fonte: elaborado pela autora, 2018. 
O cluster amarelo encontra-se conectado aos clusters vermelho, azul-claro, roxo e verde. Schunn e Crhistensen são os autores que possibilitam tais relações, citados juntamente com Dong, Kleinsmann, Eppinger, Schon, Simon, (cluster vermelho), Gross (cluster azul-claro), Mehalik (cluster roxo), e Agogino (cluster verde).

Figura 4 - clusters conectados diretamente ao cluster amarelo

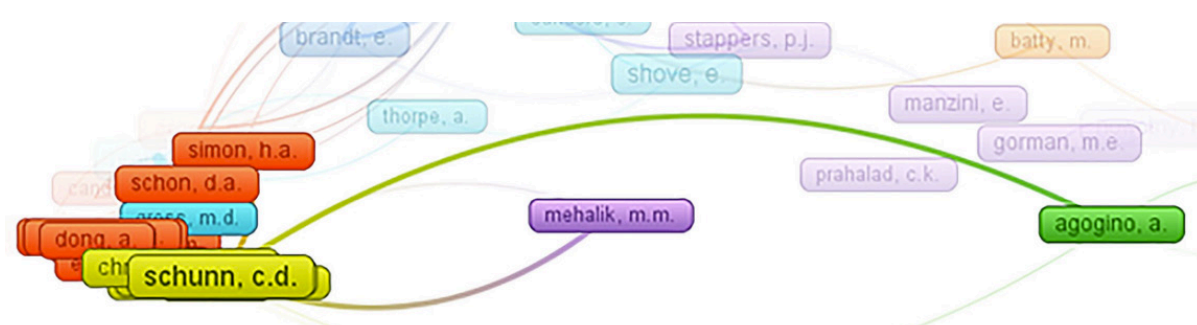

Fonte: elaborado pela autora, 2018.

Os autores dos clusters conectados ao amarelo, como indica a pesquisa por autor da Scopus, produzem sobre Engenharia e Ciência da Computação, consistindo em uma corrente teórica inserida na área de Ciências Exatas. Isso indica uma forte interdisciplinaridade nas pesquisas sobre design colaborativo e sustentabilidade, pois a priori compreende-se o design como uma área das ciências humanas ou ciências sociais aplicadas. Por mais que seja essa mesma a vertente das pesquisas, quando se trata de ferramentas para a sustentabilidade e inovação em tecnologia, as ciências exatas têm forte presença.

O próximo cluster a ser analisado é o cluster azul, cujo principal autor é Johan Colding, pesquisador da ciência ambiental, ciências sociais, economia, biologia e neurociência. Suas publicações são sobre sustentabilidade urbana e desenvolvimento socioeconômico nas cidades. Na rede de cocitações gerada pelo Vosviewer, Colding possui 9 citações. O segundo principal autor é Eva Brandt, da 
Quantificação da produção científica... e sustentabilidade DEVERGENES, N. M; CAVALCANTE, A. L. B. L

Mesmo que os conceitos "design social" e "design para o mercado" estejam inicialmente em oposição, na literatura e na prática eles se fundem. 
área de Computação, Engenharia e Artes e Humanidades. Seus artigos (18 no total) são sobre Design Democrático, Design Participativo e Design Colaborativo, os quais apenas dois foram publicados em autoria individual. A autora é a responsável na rede por relacionar as correntes teóricas do cluster vermelho, que toca as ciências exatas, e as do cluster azul, sobre sustentabilidade ambiental. Mesmo usando tais correntes teóricas como base, sua produção pode ser inserida nas abordagens humanas e sociais do design. Conectados ao cluster azul, observa-se 4 clusters: o vermelho (sobre engenharia e ciência da computação), o cor-de-rosa, o azul-claro, o roxo e o laranja.

Figura 5 - Relações que orbitam o cluster azul

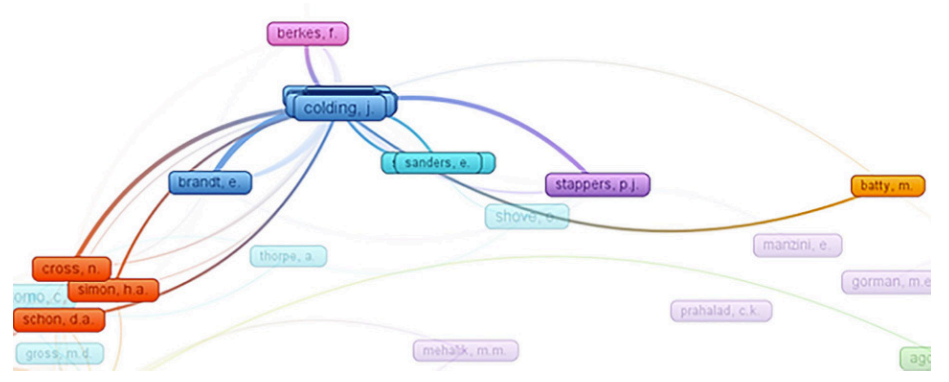

Fonte: elaborado pela autora, 2018.

Figura 6 - Autores relacionados a Eva Brandt

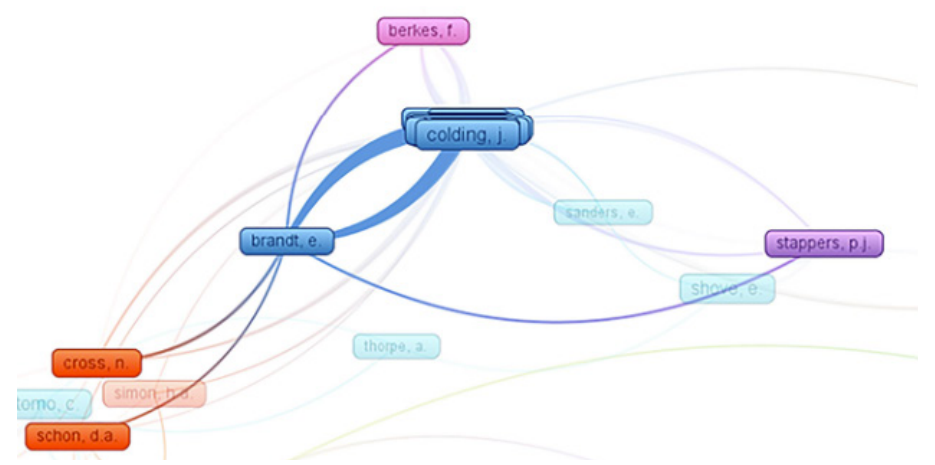

Fonte: elaborado pela autora, 2018. 
O cluster rosa é formado por apenas dois autores: Fikret Berkes, que publica sobre sustentabilidade social e ambiental. Seus artigos têm a ver com a resiliência de comunidades colaborativas, grupos sociais situados em determinados espaços geográficos. Ele é cocitado com John C. Z. Woinarski, pesquisador da Ecologia.

O autor Pieter Jan Stappers é o único do cluster roxo que faz relações com o cluster azul. Publicou pesquisas sobre colaboração em design, design centrado no usuário e Interação Humano-Computador. É cocitado com Elizabeth Shove, centrada nas teorias sobre transformação social, política e ambiental. É a única autora cocitada com Ezio Manzini (2008), no cluster roxo, que é referenciado neste trabalho e publicou 'Design para a inovação social e sustentabilidade', relacionando necessidades de transformações ambientais e sociais (chamadas 'descontinuidades sistêmicas') com as práticas da nossa sociedade. No mesmo cluster está presente Gui Bonsiepe, crítico rigoroso das práticas de design contemporâneo e que publicou uma série de artigos sobre Design, cultura e sociedade, entre os quais 'Design e Democracia', no qual o autor relaciona a prática do design com a política. Também publicou em 2015 o livro 'Do material ao digital', com artigos sobre tendências do design contemporâneo no séc. XXI. Assim, o cluster roxo tem muito a ver com a sustentabilidade no âmbito social.

Figura 7 - Visão ampla do cluster roxo

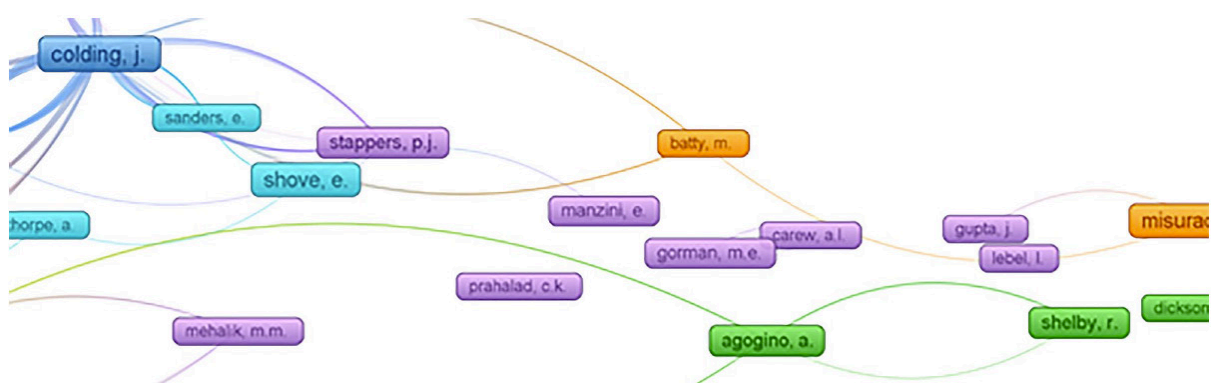

Fonte: elaborado pela autora, 2018. 
O autor Gianluca Carlo Misuraca é o principal do cluster laranja, com 7 citações. Desenvolve trabalhos sobre inovação e resiliência sociais relacionados às transformações digitais do nosso milênio, bem como estratégias de governo por meios digitais. O cluster laranja possui relações teóricas com o cluster verde, azul e roxo.

Aqui, estamos entrando numa esfera que trata da relação entre a tecnologia e as transformações sociais contemporâneas. Michael J. Batty é o autor que conecta a maioria dos autores do cluster laranja com o cluster azul, publicando estudos sobre sociologia e geografia urbanas.

Figura 8 - Principais autores que orbitam o cluster laranja

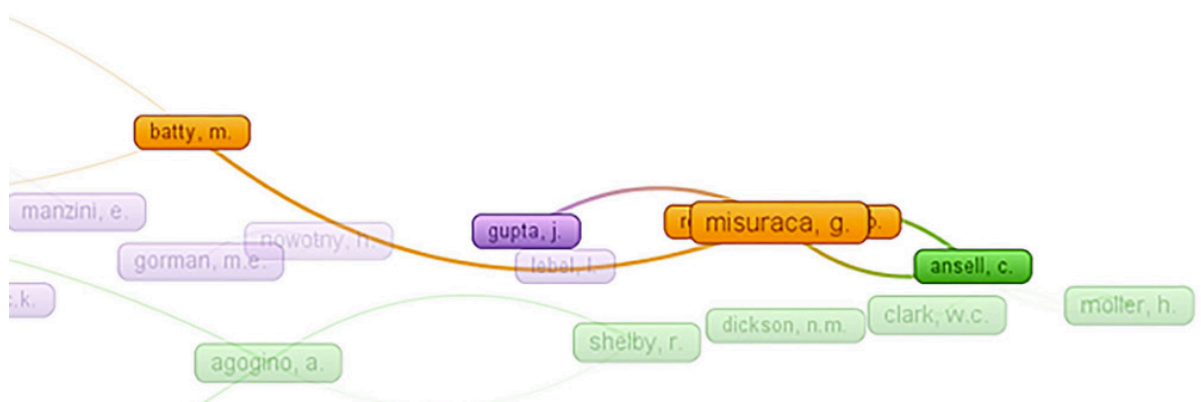

Fonte: elaborado pela autora, 2018.

Numa visão ampla do mapa de conexões teóricas entre os autores, observase que os clusters mais dispersos são o roxo e o verde. Nesses agrupamentos, os autores possuem menos relações com outros clusters, como por exemplo o verde, que só se conecta com os clusters laranja e amarelo. O Cluster verde tem como principais autores Clark, Dickson, Shelby e Agogino, todos com 4 citações. Clark se relaciona com Dickson e Moller, o qual conecta o cluster verde ao laranja. Ryan L. Shelby é autor em co-design e sustentabilidade social, e está conectado 
apenas a Alice Merner Agogino, fortemente relacionada a desenvolvimento social e tecnológico na área do design. De uma maneira geral, o cluster verde diz respeito às teorias em desenvolvimento sustentável, seja ambiental, seja social.

Figura 9 - Principais autores do cluster verde
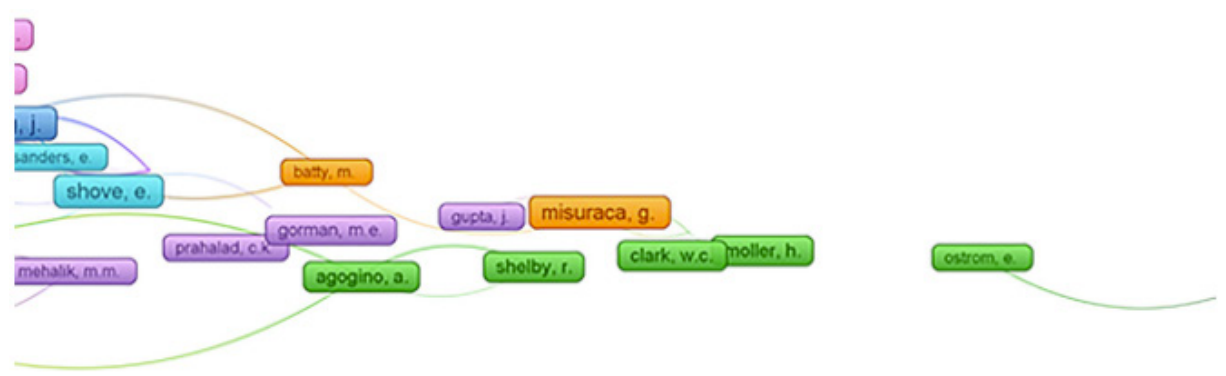

Fonte: elaborado pela autora, 2018.

Para finalizar a análise, observa-se dois autores principais isolados de todas as outras redes, um pertencente ao cluster verde e outro ao cinza, que representa uma corrente teórica multidisciplinar em gestão de recursos ambientais e inovação socioambiental.

Figura 10 - Rede de cocitações isolada com o cluster cinza
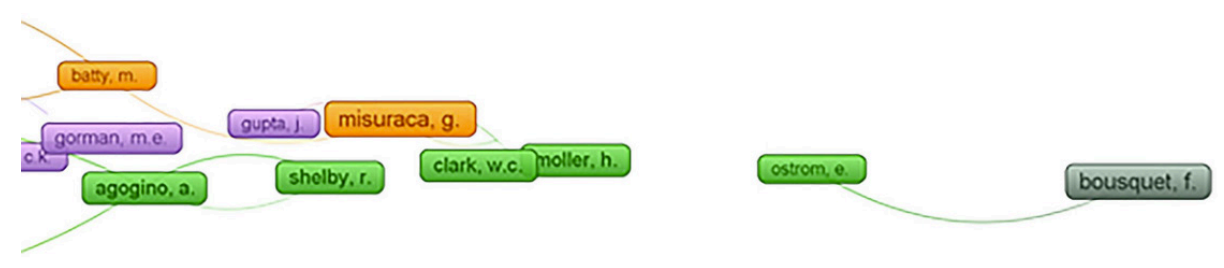

Fonte: elaborado pela autora, 2018. 


\section{CONSIDERAÇÕES FINAIS}

Realizou-se uma revisão bibliográfica sistemática e o mapeamento das redes de cocitação entre autores em Design Colaborativo e Sustentabilidade para demonstrar como os termos estão sendo tratados pela comunidade científica de design e como os autores estão teoricamente relacionados. A quantificação da produção científica serve como base de dados para identificar correntes teóricas e lacunas no conhecimento a serem exploradas. Este artigo indica a pesquisadores e pesquisadoras interessados na área quais são os principais autores relacionados aos dois temas e quais as correntes teóricas de cada um deles.

Os resultados indicam que as pesquisas na área de design colaborativo e sustentabilidade são extremamente recentes, tendo seu início em 2003. As correntes teóricas encontradas são 9 no total, indicadas por grupos de autores que são citados em conjunto (clusters categorizados por cor). As correntes teóricas categorizadas possuem caráter predominantemente interdisciplinar, de uma forma tocando os estudos em engenharia e ciência da computação, desenvolvimento sustentável ambiental e transformações sociais, que são relacionadas com a prática colaborativa e sustentável do design. Cada cluster trabalha relacionando as três áreas de sua maneira, como demonstrado na análise de cocitações.

Teoricamente, a sustentabilidade começa a ser tratada no design a partir do âmbito ambiental. As outras esferas (sociais, políticas) são exploradas pelos autores na relação com esse primeiro pensamento, o que demonstra um entendimento sistêmico dos desafios contemporâneos do design e da sustentabilidade. 
Como há apenas um cluster dedicado ao pensamento das transformações sociais (o cluster roxo) na sua relação com os processos colaborativos e sustentabilidade social no design, entende-se que o âmbito da sustentabilidade social é uma lacuna a ser mais explorada e amadurecida. Sugere-se que sejam exploradas as conexões entre os conhecimentos teóricos das ciências sociais (sociologia, antropologia e ciência política) e o conhecimento do processo de design sustentável.

As definições da prática de design na contemporaneidade estão sendo ressignificadas. Como o paradigma contemporâneo está em ascensão, entende-se que a tendência é que sejam publicados mais trabalhos na temática dos termos "design colaborativo" e "design para a sustentabilidade social", e que as discussões sobre design e sociedade sejam reforçadas no meio acadêmico. Em nome da necessidade e relevância da atuação colaborativa e socialmente sustentável do designer, defende-se que o desenvolvimento de pesquisas e práticas na área são necessárias e devem ser incentivadas. 
Projética, Londrina, v. 12, n. 1, p. 246-269, março 2021

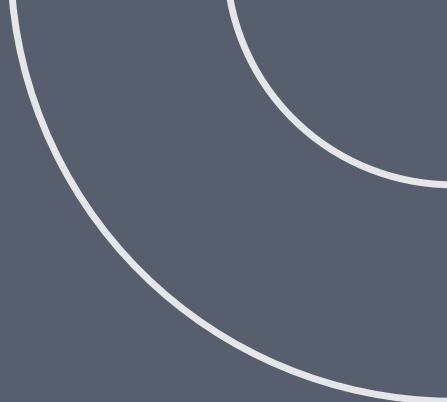

\section{REFERÊNCIAS}

1. BONSIEPE, Gui. Design e democracia. In: BONSIEPE, Gui. Design, cultura e sociedade. São Paulo: Blucher, 2011. p.17-25.

2. CAVALCANTE, Ana Luísa Boavista Lustosa; PRETO, Seila Cibele Sitta; FIALHO; Francisco Antônio Pereira; FIGUEIREDO, Luiz Fernando Gonçalves de. Design para a sustentabilidade: um conceito Interdisciplinar em construção. Projética, Londrina, v. 3, n. 1, p.252-263, 4 set. 2012. Disponível em: http:// www.uel.br/revistas/uel/index.php/projetica/article/view/12384. Acesso em: 23 nov. 2018.

3. CAVALCANTE, Ana Luísa Boavista Lustosa. Design para a sustentabilidade cultural: recursos estruturantes para sistema habilitante de revitalização de conhecimento local e indígena. 2014. 321 f. Tese (Doutorado em Engenharia e Gestão do Conhecimento) - Centro Tecnológico, Universidade Federal de Santa Catarina, Florianópolis, SC, 2014. Disponível em: https://repositorio. ufsc.br/handle/123456789/132600. Acesso em: 5 nov. 2018.

4. GRÁCIO, Maria Cláudia Cabrini; OLIVEIRA, Ely Francina Tannuri de. Análise de cocitação de autores: um estudo teórico-metodológico dos indicadores de proximidade, aplicados ao GT7 da ANCIB. Liinc em Revista, Rio de Janeiro, v. 1, n. 9, p. 196-213, maio 2013.

5. MANZINI, Enzio. Design para a inovação social e sustentabilidade: comunidades criativas, organizações colaborativas e novas redes projetuais. Rio de Janeiro: E-papers, 2008. 
Quantificação da produção científica... e sustentabilidade DEVERGENES, N. M; CAVALCANTE, A. L. B. L

6. MARGOLIN, Victor; MARGOLIN, Sylvia. A "social model" of design: issues of practiceandresearch. Design Issues, Cambridge MA, v. 18, n. 4, p. 24-30, autumn 2002. Disponível em: http://dx.doi.org/10.1162/074793602320827406. Acesso em: 6 nov. 2018.

7. MARTTILA, Tatu. Platforms of co-creation: learning interprofessional Design Practice in Creative Sustainability. 2018. 278 f. Dissertation (Master's degree in Creative Sustainability) - Department of Design, Aalto University School of Arts, Design and Architecture, Helsinki, 2018. Disponível em: https://shop. aalto.fi/media/filer_public/0a/f4/0af49d14-0ae9-4bcf-bba9-cae9e2a05038/ platforms_of_co-creation.pdf. Acesso em: 6 nov. 2018.

8. MOURA, Mônica. Design contemporâneo: poéticas da diversidade no cotidiano. In: FIORIN, Evandro; LANDIM, Paula da Cruz; LEOTE, Rosângela da Silva (org.). Arte-ciência: processos criativos. São Paulo: Cultura Acadêmica, 2015. p. 61-80. (Coleção PROPe Digital - UNESP). ISBN 9788579836244. Disponível em: http://hdl.handle.net/11449/123646. Acesso em: 6 nov. 2018.

9. REDIG, Joaquim. Design: responsabilidade social no horário do expediente. In: BRAGA, Marcos da Costa (org.). O papel social do design gráfico: história, conceitos e atuação profissional. São Paulo: Senac, 2011. p. 87-113.
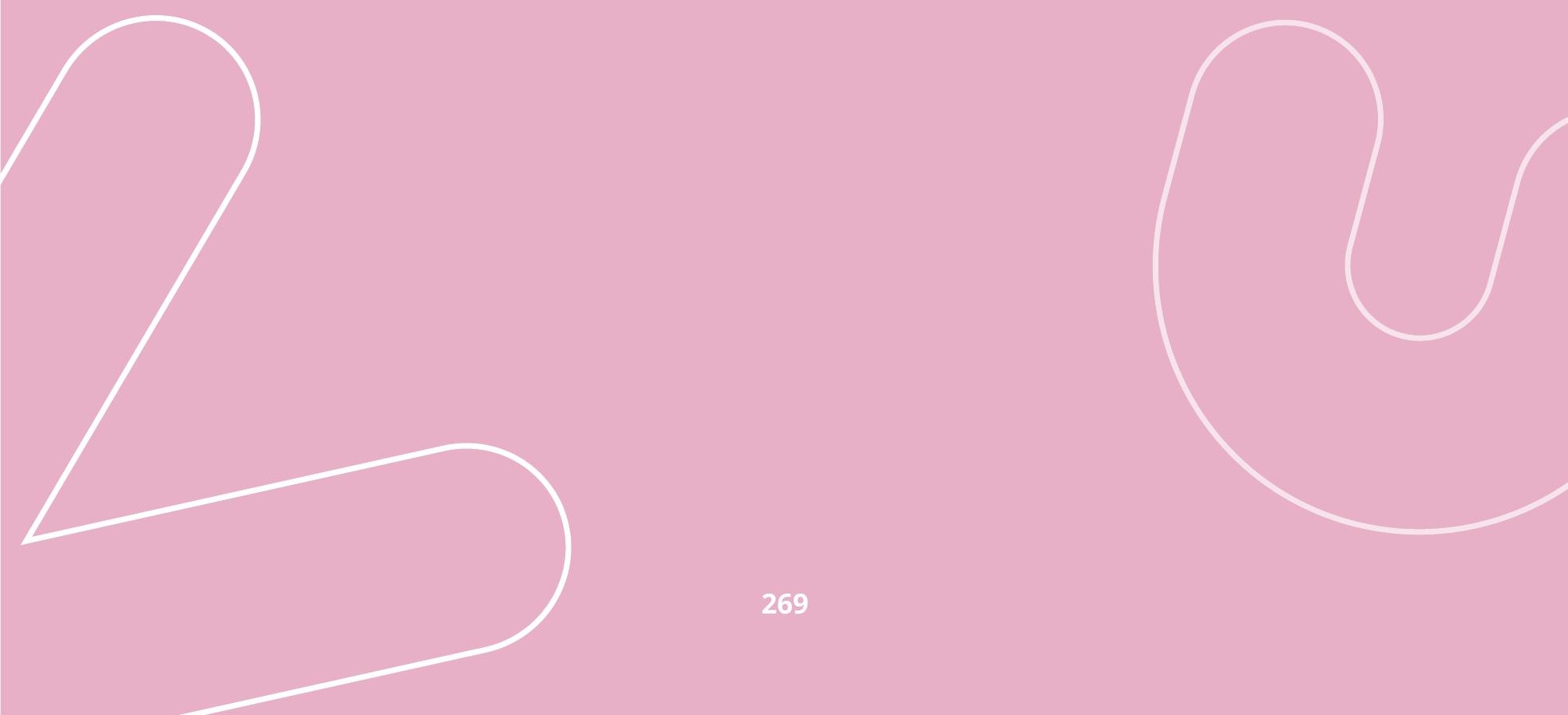